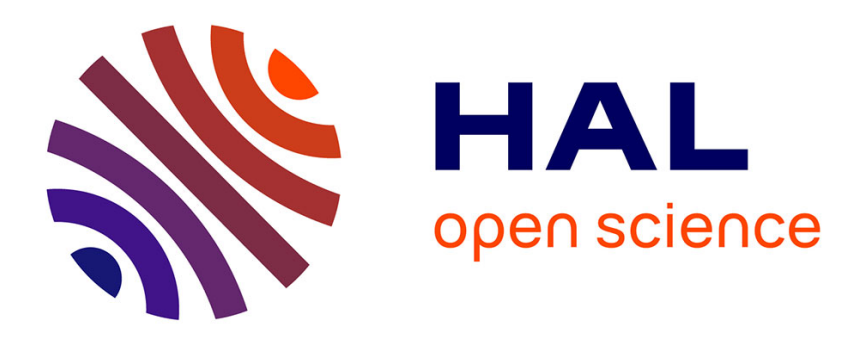

\title{
Behavioral Economics and Regulatory Analysis
}

Lisa A. Robinson, James K Hammitt

\section{To cite this version:}

Lisa A. Robinson, James K Hammitt. Behavioral Economics and Regulatory Analysis. Risk Analysis, 2011, 31 (9), pp.1408-1422. 10.1111/j.1539-6924.2011.01661.x . hal-02651324

\section{HAL Id: hal-02651324 \\ https://hal.inrae.fr/hal-02651324}

Submitted on 29 May 2020

HAL is a multi-disciplinary open access archive for the deposit and dissemination of scientific research documents, whether they are published or not. The documents may come from teaching and research institutions in France or abroad, or from public or private research centers.
L'archive ouverte pluridisciplinaire HAL, est destinée au dépôt et à la diffusion de documents scientifiques de niveau recherche, publiés ou non, émanant des établissements d'enseignement et de recherche français ou étrangers, des laboratoires publics ou privés. 


\title{
Behavioral Economics and Regulatory Analysis
}

\author{
Lisa A. Robinson ${ }^{1}$ and James K. Hammitt ${ }^{2}$ \\ June 2011
}

\begin{abstract}
Behavioral economics has captured the interest of scholars and the general public by demonstrating ways in which individuals make decisions that appear irrational. While increasing attention is being focused on the implications of this research for the design of risk-reducing policies, less attention has been paid to how it affects the economic valuation of policy consequences. This article considers the latter issue, reviewing the behavioral economics literature and discussing its implications for the conduct of benefit-cost analysis, particularly in the context of environmental, health, and safety regulations. We explore three concerns: using estimates of willingness to pay or willingness to accept compensation for valuation, considering the psychological aspects of risk when valuing mortality-risk reductions, and discounting future consequences. In each case, we take the perspective that analysts should avoid making judgments about whether values are "rational” or "irrational.” Instead, they should make every effort to rely on well-designed studies, using ranges, sensitivity analysis, or probabilistic modeling to reflect uncertainty. More generally, behavioral research has led some to argue for a more paternalistic approach to policy analysis. We argue instead for continued focus on describing the preferences of those affected, while working to ensure that these preferences are based on knowledge and careful reflection.
\end{abstract}

\footnotetext{
${ }^{1}$ Independent Consultant, Newton, MA. Lisa.A.Robinson@comcast.net

${ }^{2}$ Harvard University (Center for Risk Analysis) and Toulouse School of Economics (LERNA-INRA). jkh@harvard,edu
} 


\subsection{INTRODUCTION}

Economic theory and research have yielded important advances in the design and implementation of policies to reduce environmental, health, and safety risks. Economic analysis has also been part of the regulatory decisionmaking process for over 30 years, as a result of U.S. government requirements for the conduct of benefit-cost analysis. Such analysis is based on the standard neoclassical economic model, which is being increasingly challenged by research in behavioral economics. This behavioral research is leading to innovations in policy design and implementation (such as greater focus on information disclosure) and to improved understanding of how individuals are likely to respond to program features. Less attention has been paid to how it might affect the valuation of outcomes in benefit-cost analysis. In this article, we focus on this latter issue, reviewing the implications of behavioral research for the economic assessment of environmental, health, and safety regulations.

Benefit-cost analysis supports risk management decisions by providing information about the preferences of affected individuals for spending on risk reductions. To facilitate comparison to costs and to indicate both the direction and intensity of preferences, analysts value benefits such as health and environmental improvements in monetary terms to the extent possible and discount them to reflect time preferences. Because such outcomes often are not directly bought and sold in the marketplace, analysts estimate their value based on revealed- and statedpreference studies. These studies rely on individual behavior or reported choices to estimate monetary values for nonmarket goods. Research in behavioral economics is now questioning the extent to which individual choices, such as those reflected in these studies, are consistent with individual preferences and well-being.

The implications of this research may be particularly significant in the context of Federal environmental, health, and safety regulations. The impact of these regulations is substantial. Over the past 10 years, Federal agencies have promulgated over 95 major rules with over \$85 billion in annual net benefits (2001 dollars). ${ }^{(1) 1}$ Of this total, 30 were promulgated by the U.S. Environmental Protection Agency (EPA), 11 by the National Highway Traffic Safety Administration, and 10 by the U.S. Food and Drug Administration. In monetary terms, EPA rules dominate the totals; over this period, it finalized rules leading to well over $\$ 56$ billion in annual net benefits.

While research in behavioral economics challenges some of the theoretical assumptions that underlie the current analytic requirements for these rules, the magnitude and pervasiveness of many of these deviations are not yet clear. In addition, these deviations often depend on context and more work is needed to determine whether the deviations found in the contexts frequently studied (e.g., financial decisions) are important in the environmental, health, and safety context. Thus we are writing at a time when behavioral economics raises questions or suggests alternatives in need of further exploration and consideration, but does not lead to conclusive resolution of the underlying issues.

In the following sections, we begin by summarizing the current requirements for assessing major Federal regulations. We then provide an overview of related behavioral research and explore three issues in more detail: whether willingness to pay or to accept compensation is

\footnotetext{
${ }^{1}$ Authors' calculations from Tables 1-1 and 1-2, pp. 12-13. These counts understate the impact of Federal regulations because some outcomes of these rules are not fully quantified or monetized . A significant omission is that the benefits of rules issued by the U.S. Department of Homeland Security are generally not quantified due to difficulties inherent in predicting their effects.
} 
the appropriate measure for valuation, how psychological responses affect the value of mortalityrisk reductions, and whether discounting of future benefits and costs should be exponential or hyperbolic. We select these topics because they have significant implications for the conduct of regulatory analysis and represent areas where research in behavioral economics is reasonably well-developed. We conclude by discussing the role of benefit-cost analysis in risk policy decisions more generally, in light of this research.

\subsection{REQUIREMENTS FOR REGULATORY ANALYSIS}

In the U.S., the basic principles for regulatory analysis are established in Executive Order $12866,{ }^{(2)}$ which requires that Federal agencies assess alternative policies for actions that may be economically significant; i.e., may lead to a rulemaking that has an annual economic effect of $\$ 100$ million or more or has important adverse effects. ${ }^{2}$ Agencies may regulate only when they can reasonably determine that the benefits justify the costs and are required to select regulatory approaches that maximize net benefits (unless restricted by statute). The Executive Order defines benefits broadly to include effects that cannot be quantified as well as equity considerations. The Obama Administration supplemented and reaffirmed this guidance in Executive Order 13563. ${ }^{(4)}$

To aid in implementing these assessments, the U.S. Office of Management and Budget (OMB) issued Circular A-4, Regulatory Analysis ${ }^{(5)}$ and summarized and clarified related requirements in a checklist for agencies. ${ }^{(6)}$ The Circular covers several topics, including determining the need for Federal regulatory action, defining alternative regulatory options, applying various analytic approaches (including benefit-cost analysis, cost-effectiveness analysis, and analysis of distributional effects), measuring costs and benefits (including discounting and treatment of uncertainty), and complying with related Executive Orders and statutes. It specifies requirements that $\mathrm{OMB}$ expects agencies to follow and provides information on preferred practices. The Circular recognizes that agencies' ability to adhere to these practices may be limited by available scientific research or other constraints and notes the importance of professional judgment. At the same time, the Circular is intended to help standardize how agencies conduct these assessments. Ultimately, the details of the analytic approach are negotiated between OMB and agency staff as part of OMB's review of each rulemaking. ${ }^{3}$

OMB Circular A-4 was drafted at a time when research in behavioral economics was beginning to receive more widespread attention. It references some behavioral work (such as Kahneman et al., ${ }^{(8)}$ discussed below) but has not yet been amended to incorporate more recent research in this area. The Obama Administration has indicated its interest in behavioral considerations, for example by appointing Cass Sunstein as the Administrator of OMB's Office of Information and Regulatory Affairs. As a legal scholar, Professor Sunstein significantly enhanced our understanding of the implications of behavioral research for public policy. Perhaps most famously, in Nudge ${ }^{(9)}$ he and Richard Thaler argue that choices should be structured to address behavioral biases, encouraging individuals to make welfare-enhancing decisions.

Sunstein is also a strong advocate of benefit-cost analysis, viewing it as needed to counterbalance potential cognitive errors and biases, suggesting the need for "wider and deeper" analysis, and applauding the movement of the U.S. towards a "cost-benefit state."(10,11,12) At the same time, he recognizes some of the psychological phenomena discussed by behavioral

\footnotetext{
${ }^{2}$ Executive Order 12866 superseded the generally similar Executive Order 12291. ${ }^{(3)}$

${ }^{3}$ See Graham $^{(7)}$ for a detailed review of the use of benefit-cost analysis in Federal regulatory development and recommendations for improvement.
} 
economists imply that individuals' reported willingness to pay may be inconsistent with their own welfare. $^{(13)}$

While benefit-cost analysis traditionally focuses on economic efficiency, Sunstein is also concerned about the distribution of costs and benefits, emphasizing the need to consider fairness. ${ }^{(13)}$ He argues, for example, that mortality risks should be valued more highly for younger than older individuals in part on equity grounds. ${ }^{(14)}$ He is also sensitive to the uncertainties inherent in these analyses, indicating that they provide useful information on the possible outcomes; where outcomes or values are uncertain, he suggests that agencies use a reasonable range. ${ }^{(10,15)}$

At OMB, Sunstein has issued statements discussing behaviorally-informed approaches to regulation and the need for information disclosure, ${ }^{(16)}$ clarifying guidance for regulatory analysis $^{(1)}$ and reinforcing related requirements of Executive Order 13563 . $^{(17)}$ The statements on regulatory analysis focus largely on improving how agencies communicate the approach and results and on identifying factors that should be emphasized. They do not discuss the potential for major methodological changes given the results of behavioral research, which is the main focus of this article.

\subsection{BEHAVIORAL ECONOMICS AND BENEFIT-COST ANALYSIS}

Because all economics is concerned with how people behave, the dividing line between behavioral and neoclassical economics is not always clear - the two schools may be distinguished more by what they emphasize than by any sharp differences in approach. Behavioral economists often note that, in its simplest form, the standard economic model assumes that people behave self-interestedly and rationally (as “econs” or "homo economicus”) while they incorporate insights from psychology, sociology, and other fields to consider how human behavior may deviate from this model. For example, Thaler and Mullainathan ${ }^{(18)}$ argue that the standard economic model assumes three unrealistic traits: unbounded rationality, unbounded willpower, and unbounded selfishness. Bounded rationality recognizes that our limited capacity to process information may lead us to make suboptimal decisions. Bounded willpower recognizes that our incomplete self-control may cause us to engage in behaviors we know we will regret. Bounded selfishness refers to the fact that we may act selflessly.

This characterization oversimplifies the neoclassical model and ignores perhaps the most important source of disagreement with behavioral economics. One oversimplification is the discussion of selfishness; other-regarding preferences such as altruism (e.g., Jones-Lee, ${ }^{(19)}$ Bergstrom $^{(20)}$ ) and existence values for natural environments (e.g., Krutilla ${ }^{(21)}$ ) have been examined within the standard model. More fundamentally, the neoclassical model typically incorporates expected utility theory to describe decisionmaking under uncertainty. ${ }^{4}$ Expected utility theory assumes that preferences are defined over consequences rather than over changes from some reference point and that changes in the probability of a consequence are treated linearly. To accommodate increasing empirical evidence that behavior often violates these assumptions, Kahneman and Tversky ${ }^{(24)}$ developed prospect theory, which forms a basis for much subsequent behavioral research. Prospect theory describes how individuals tend to underweight outcomes that are probable in comparison to those that are certain, to be more sensitive to differences in probability near zero and one than to intermediate probabilities, to be

\footnotetext{
${ }^{4}$ Alternatives to expected utility theory are also examined within the neoclassical tradition (e.g., Machina ${ }^{(22,23)}$ ).
} 
loss averse (overweighting losses relative to gains), and to be sensitive to the form in which a choice is presented.

While work on these issues can be traced back over decades, it has exploded in recent years. ${ }^{5}$ For example, a full text search for "prospect theory" in the EconLit database yields 33 articles published in peer-reviewed journals from 1980 to 1995, increasing to 230 articles from 1996 to $2009 .{ }^{6}$ This increase in scholarly output has been accompanied by increased emphasis in the popular press, in part due to the publication of bestsellers such as Thaler and Sunstein's Nudge $^{(9)}$ and Dan Ariely's Predictably Irrational ${ }^{(32)}$ (both in 2008).

Benefit-cost analysis is mentioned relatively infrequently in this literature but has begun to receive more attention. Bernheim and Rangel ${ }^{(33)}$ frame the issues in a way that is particularly useful. They note that "[p]ublic economics has positive and normative objectives; it aims both to describe the effects of public policies and to evaluate them. This agenda requires us to formulate models of human decision-making with two components - one describing choices, and the other describing well-being. Using the first component, we can forecast the effects of policy reforms on individuals' actions, as well as on prices and allocations. Using the second component, we can determine whether these changes benefit consumers or harm them” (p. 7). This distinction between behavior and welfare is not necessary under the traditional economic model because that model assumes that individuals choose what they want; i.e., that their preferences are revealed through their behavior.

While there is no consensus on how to evaluate welfare given this distinction, Bernheim and Rangel describe two schools of thought. One is to continue to rely on revealed preferences to evaluate welfare, but to expand how we think about preferences to include deviations from the standard model. The second is to modify, or even reject, the reliance on revealed preferences, suggesting that preferences should be used to measure welfare only in those cases where they appear consistent with the individual's self-interest. While potentially protecting against errors, this more paternalistic approach runs into the possibility of abuse if individual preferences can be overridden without adequate, evidence-based justification. This tension between unquestioning acceptance of individual choices and acceptance of only those that are judged to be rational and welfare-enhancing is at the heart of many of the implications of behavioral economics for the conduct of benefit-cost analysis.

Behavioral economics has not yet developed into a unified theory that provides a cohesive alternative or supplement to the standard economic model. While some models have been proposed, none are currently widely accepted. An example is the "choice-theoretic" model developed by Bernheim and Rangel, ${ }^{(34)}$ which distinguishes between "choice conditions" and "ancillary conditions." The former are unchanging attributes of the choice itself, while the latter depend on the decision-maker or context. Distinguishing between observed choices that do and do not reflect such ancillary conditions is challenging, particularly for outcomes (such as environmental improvements or health-risk reductions) that are not traded in markets and for which we have limited information on how values change among contexts.

An alternative approach is proposed by Sugden, ${ }^{(35,36,37)}$ who advocates a "marketsimulation” strategy. He develops decision rules that consider what an individual would be willing to pay immediately prior to consumption, focusing on the nearest market analog when valuing nonmarket goods. His framing does not require that an individual be willing to make the

\footnotetext{
${ }^{5}$ Seminal articles are collected in Kahneman, Slovic, and Tversky, ${ }^{(25)}$ Thaler ${ }^{(26)}$ Kahneman and Tversky, ${ }^{(27)}$ and Camerer, Loewenstein, and Rabin. ${ }^{(28)}$ Reviews include Rabin, ${ }^{(29)}$ Fudenberg, ${ }^{(30)}$ and DellaVigna. ${ }^{(31)}$

${ }^{6}$ Search conducted on September 8, 2010.
} 
same exchange at different points in time or from different reference states: it only requires that the individual is sensitive to price. However, he excludes certain types of preferences by favoring "at the moment" decisions regardless of whether they differ from those that may be made in a cooler emotional state or with more reflection. His framework cannot easily accommodate outcomes that lack market analogues, such as the value of simply knowing that special features of the natural environment exist.

Smith and Moore ${ }^{(38)}$ review these proposals and conclude that they do not provide an adequate basis for policy analysis. They propose an alternative framing that recognizes that observed choices reflect a number of constraints, noting that: "[d]ecisions that appear incoherent or contradictory may simply reflect the analysts' failure to fully specify the constraints to choice” (p. 226). They illustrate this framing by discussing limitations such as variation in cognitive capacity, the energy available for decisionmaking, and physical dexterity, as well as budget constraints.

Regardless of which, if any, of the proposed theoretical models is ultimately accepted, empirical research in behavioral economics is relevant to several issues discussed in the guidance contained in OMB Circular A-4. Consistent with the neoclassical model, the Circular focuses on the use of benefit-cost analysis to assess economic efficiency; i.e., to identify the regulatory option (including the option of no action) that maximizes net benefits regardless of who bears the costs or who receives the benefits. Both the Circular and the Executive Orders it implements emphasize the need to also provide information on the distribution of the effects so that decisionmakers can determine the extent to which equity considerations should outweigh efficiency. In this article, we focus on how information about individual preferences is used to identify the economically-efficient regulatory option.

Throughout the discussion that follows, we generally take the perspective that analysts should avoid making judgments about whether values are "rational” or "irrational," but should make every effort to ensure that studies are designed to elicit well-informed, thoughtful preferences. "Mistakes” or "errors" may occur where individuals make choices that diverge from how they would define their own preferences given access to information, adequate reflection, and self-control, absent the biases that may result from cognitive or other challenges. While such perfection in decisionmaking may be impossible in reality, our hope is to avoid paternalistic views of what individuals "should" prefer, deferring to the preferences individuals express when provided opportunities for contemplation and learning. In other words, consistent with the notion of "consumer sovereignty" that is embedded in the neoclassical economic model, we maintain the traditional reliance on individuals' own definition of their welfare while recognizing that education and experience may be needed to aid them in developing this definition.

\subsection{WILLINGNESS TO PAY VERSUS WILLINGNESS TO ACCEPT COMPENSATION}

Federal regulations often address outcomes, such as health-risk reductions and environmental improvements, that are not directly traded in markets. Because market prices are not available, the value of these outcomes is estimated through revealed- or stated-preference research.

Revealed-preference studies use data from market transactions or observed behavior to estimate the value of related nonmarket goods, while stated-preference studies involve asking respondents how they would behave in a hypothetical market. One issue that arises is whether values should 
be based on willingness to pay (WTP) or willingness to accept (WTA) compensation. ${ }^{7}$ For a beneficial outcome, WTP represents the maximum amount of money an individual would be willing to give up in exchange for the amenity (e.g., for a risk reduction resulting from a regulation that decreases air pollution); WTA represents the minimum amount he would need to be paid to forego, rather than gain, the improvement. WTP and WTA also can be used to value harmful changes, in which case WTP is the maximum an individual would pay to avoid the harm and WTA is the minimum he would require to accept the harm.

\subsection{Description of the Issue}

Under conventional assumptions, Willig ${ }^{(43)}$ demonstrates that for private goods, where the individual can choose the quantity consumed, WTP and WTA should be similar as long as income effects are negligible. Hanemann ${ }^{(44)}$ finds that for public goods, where the individual cannot choose the quantity, WTP and WTA can diverge when there are no private goods that are close substitutes. Many empirical studies have found substantial differences between WTP and WTA. ${ }^{(45)}$ Behavioral economists argue that these differences cannot be fully explained by income and substitution effects. Kahneman, Knetsch, and Thaler ${ }^{(8)}$ and several subsequent studies highlight the implications of prospect theory for this divergence, identifying it as a major concern for benefit-cost analysis.

Knetsch ${ }^{(46,47)}$ notes that behavioral studies indicate that WTP and WTA differ due to the combination of two factors, loss aversion and the endowment effect. Loss aversion implies that individuals will value the change more highly if it is viewed as a loss rather than as a gain from their reference state. The endowment effect determines whether individuals view their present state or their state after the change as the reference state. Thus, if the reference state is one's current status, WTP for a gain will be smaller than WTA for a loss of the same magnitude. Knetsch notes that the extent of this discrepancy may be small in the case of many day-to-day market transactions but appears larger for environmental amenities where the feeling of entitlement may be stronger.

This divergence raises the question of which measure is most appropriate for regulatory analysis, the answer to which requires determining the appropriate reference state. Some economists $^{(48)}$ as well as OMB Circular A-4 $4^{(5)}$ suggest that the choice should depend on property rights (i.e., legal entitlements). For beneficial changes, if the property right is associated with the current state, then WTP to obtain an improvement is the correct measure. If the property right is associated with the change, then WTA to forgo the improvement is the correct measure. However, particularly for nonmarket goods, entitlements are often not well-defined. Moreover, when the same population receives the benefits and pays the costs (e.g., of a program to improve drinking-water quality by enhancing a municipal treatment facility), it may not make sense to distinguish a right to the benefit as distinct from responsibility for the costs.

\footnotetext{
${ }^{7}$ We focus on individual WTP or WTA for private goods; e.g., changes in one's own risks. Some regulatory policies provide public goods; e.g., improving environmental quality for the entire community of which one is a part. In this context, other-regarding (or social) preferences may noticeably increase or decrease WTP, but more work is needed to determine the direction and magnitude of these effects. Some such preferences (such as altruism) have been explored within the neoclassical model (e.g., Jones-Lee, ${ }^{(19)}$ Bergstrom $^{(20)}$ ) and behavioral economists have identified other types of social preferences. ${ }^{(39,31)}$ However, the effects on preferences for public environmental, health and safety programs have been addressed to only a very limited extent in empirical research ${ }^{(40,41,42)}$ and the results are diverse, inconclusive, and context-dependent.
} 
An alternative approach is to consider what the affected individuals consider to be their normal or expected state when assessing their own welfare. As Knetsch ${ }^{(47)}$ notes, intuition might guide how to define the reference state in this case but research is needed to confirm this intuition in different contexts. Status-quo bias (a preference for the current state), which is closely related to the endowment effect and loss aversion, may also affect how individuals define the reference state. ${ }^{(49,8)}$

Policy analysts often rely on WTP estimates for more pragmatic reasons, including skepticism about WTA estimates that appear implausibly large. This issue arises primarily when stated-preference methods are used for valuation, as revealed-preference methods can rarely distinguish between WTP and WTA. As discussed by Smith and Moore, ${ }^{(38)}$ the hedonic models used in many revealed-preference studies (such as those examining wage-risk trade-offs to estimate the value of mortality-risk reductions) result in point estimates of marginal WTP based on equilibrium conditions. Information on discrete changes is needed to detect disparities between WTP and WTA.

In stated-preference studies, divergence between WTP and WTA may stem, at least in part, from difficulties in eliciting preferences using hypothetical scenarios rather than from the anomalies identified by Knetsch and others. While well-conducted studies are designed to ensure that responses are as credible as possible, the reasonableness of WTP estimates can be easier to confirm. Because WTP cannot exceed an individual's ability to pay (including wealth and borrowing capacity), researchers can remind respondents to consider their budget constraints and can identify values that appear unrealistic given reported income levels. In contrast, WTA amounts are unconstrained and may lead respondents to overstate what they would in fact accept. Large values also may be reported as protest bids when respondents do not accept the scenario presented by the researchers.

\subsection{Implications for Regulatory Analysis}

If reliable estimates of both WTP and WTA are available but diverge significantly, the analyst faces two choices. He could select the measure that appears most consistent with how the affected individuals define the change from the reference state (depending on whether a policy results in a gain or a loss from that state) or could test how the results of the analysis vary depending on the estimate used. However, these approaches could lead to recommendations that differ depending on the perspective, which seems nonsensical (particularly if the same individuals bear the costs and receive the benefits). For example, an ex ante evaluation of a proposed regulation could support a different conclusion than an ex post evaluation of an existing regulation; introducing a new regulation could be evaluated differently than abolishing it once it exists. Comparing two programs with the same net physical outcome (e.g., 10 lives saved) could lead to different net benefits if one involves both losses and gains and the other involves only gains. $^{8}$ The extent to which these sorts of problems arise will depend on the extent to which the values vary when viewed from differing perspectives; for many outcomes these differences have not yet been well-studied.

\footnotetext{
${ }^{8}$ Even under conventional welfare economics, intransitivities can arise (e.g., the Scitovsky reversal paradox) and the valuation of an intervention can depend on how its benefits and costs are distributed; e.g., policies that prevent the same number of expected fatalities can be valued differently depending on how the risk reductions are concentrated or diffused in the population. ${ }^{(50,51)}$
} 
The current guidance for regulatory analysis does not explore these issues in detail, following the conventional practice of focusing on WTP for pragmatic reasons. OMB Circular A-4 $4^{(5)}$ usually refers to WTP when discussing the preferred approach to valuation, indicating that it "is generally considered to be more readily measurable" (pp. 18-19). It only briefly notes that WTA is also a valid measure and references early work ${ }^{(8)}$ on empirical disparities.

Increased attention to this issue seems desirable in any update to the OMB guidance, given the potential significance of WTP and WTA disparities, uncertainty about which measure is more appropriate in various policy settings, and uncertainty about the extent to which these disparities result from problems other than the anomalies identified by behavioral economists. Such guidance could suggest that more study is needed to understand why WTP and WTA estimates diverge for particular types of outcomes and to estimate the size of the difference. In the interim, analysts can test the sensitivity of their findings to variation in these values. For example, if the benefits analysis relies on WTP estimates but consideration of the reference state and loss aversion suggests that WTA may be more appropriate, then the analyst may wish to test the impact of larger values on the results.

\subsection{RISK PERCEPTION AND VALUATION}

Behavioral research highlights ways in which psychological responses may lead to values that appear irrational or inconsistent with the standard economic model other than the distinction between WTP and WTA. Some of these issues relate to the cognitive processing of risk information, including the misinterpretation of probabilities and the tendency to rely on simple heuristics or decision rules. However, preferences also may depend on how individuals perceive different types of risk. In this section, we explore these issues in the context of mortality-risk valuation, both because these values are well-studied and because they often dominate the benefit estimates for environmental, health, and safety regulations. ${ }^{9}$

By convention, the value of these risks is typically expressed as the value per statistical life (VSL), which represents the rate at which an individual will pay for small risk changes (e.g., 1 in 10,000) in a defined time period. In other words, it is the local slope of an indifference curve between risk and wealth (or the value of a small incremental change in mortality risk), not the value of saving an individual's life with certainty. ${ }^{(57) 10}$ There is substantial evidence that both personal characteristics and risk characteristics affect VSL; its variation is not limited to the potential differences between WTP and WTA discussed above. The influence of personal characteristics (such as income or age) can be described at least in part by standard economic theory, such as the lifecycle consumption model. ${ }^{(59,60,61,62)}$ Risk characteristics include both physical attributes (such as whether the risk is latent or involves significant morbidity prior to death) and psychological attributes (such as whether the risk is perceived as voluntarily incurred

\footnotetext{
${ }^{9}$ Recent VSL meta-analyses identify about 60 revealed-preference studies ${ }^{(52)}$ and more than 70 stated-preference studies. ${ }^{(53)}$ The importance of mortality risks is exemplified by recent analysis of the costs and benefits of the Clean Air Act, which indicate that mortality risks account for almost 90 percent of the monetized benefits in the year $2020 .{ }^{(54)}$ These risks are also a major determinant of the benefits of other rules, accounting for 60 percent or more of the injury-related benefits of the U.S. Department of Transportation's electronic stability control rule ${ }^{(55)}$ and over 80 percent of the monetized benefits of the U.S. Food and Drug Administration's trans-fat rule. ${ }^{(56)}$

${ }^{10}$ The VSL is sometimes described as the value per prevented fatality (VPF). The U.S. Environmental Protection Agency is discussing using the terms "value of mortality risk" (VMR) or "value of risk reduction" (VRR) with its Science Advisory Board, to reduce the tendency to confuse the value of these small risk changes with the value of an individual's "life. ${ }^{(58)}$
} 
or under an individual's control). For example, the available research suggests that more feared and ambiguous risks may be valued as much as twice as highly as the job-related risks that are the focus of many VSL studies. ${ }^{(63) 11}$

\subsection{Description of the Issue}

Variation in the value of mortality-risk reductions is not necessarily inconsistent with the standard economic model: changes in attributes are expected to lead to changes in value. However, some research findings, particularly from stated-preference studies, illustrate the influence of the types of anomalies emphasized by behavioral economists. First, when faced with uncertain risk information, individuals respond differently than when faced with a more precise estimate, reflecting ambiguity aversion. ${ }^{12}$ For example, work by Viscusi et al., ${ }^{(68)}$ Shogren, ${ }^{(69)}$ and Riddel and Shaw ${ }^{(70)}$ suggests that WTP for fatal or nonfatal risk reductions increases as risk ambiguity increases. Second, research shows that individuals tend to overweight small risks (particularly when they are viewed as fearsome), ${ }^{(71)}$ consistent with prospect theory. Third, individuals are often insensitive to small changes in risks, reporting the same or similar values for risk reductions that differ in magnitude. ${ }^{(72,73)}$ Although these findings may in part reflect misunderstanding or miscommunication of the risks being valued, they may also reflect stable underlying preferences.

\subsection{Implications for Regulatory Analysis}

Many VSL studies have been completed since OMB Circular A-4 was developed in 2003. In the Circular, OMB does not recommend a specific VSL, noting that related estimates are subject to continued research and debate. However, it indicates that the majority of the VSL estimates range from roughly $\$ 1$ million to $\$ 10$ million (no dollar year reported). ${ }^{13}$ Most agencies use estimates within this range, with central values generally between \$5 million and \$8 million when expressed in 2007 dollars. ${ }^{\text {(77) }}$ This range is similar to the values found in several metaanalyses. ${ }^{14}$ Circular A-4 suggests that the then-available research evidence was not adequate to support adjustment of these estimates for many differences in context, such as the population and

\footnotetext{
${ }^{11}$ Several scholars have considered the appropriate treatment of fear (e.g., Sunstein, ${ }^{(64,65)}$ Adler ${ }^{(66)}$ ). Fear can have real resource costs (due, for example, to investment in protective measures) and is one of the psychological attributes that may affect individual WTP for risk reductions. However, in some cases it may be more appropriate to address fear through risk communication or other strategies rather than incorporate it in the values used in regulatory analysis. Analysts also need to be careful to separate the effects of fear on the value of particular outcomes (such as mortality risks) from its effects more generally.

${ }^{12}$ The distinction between uncertain and ambiguous risks is not always clear. In principle, an uncertain probability may have a (subjective) expected value but an ambiguous one cannot. In his seminal work on this topic, Ellsberg ${ }^{(67)}$ notes that ambiguity depends on the amount, type, reliability, and unanimity of information on probabilities and the resulting degree of confidence one has in the data. He indicates that many people prefer payments that they will receive with certainty to those that are uncertain, even when the uncertain outcome has a higher expected value. ${ }^{13}$ This range is consistent with the advice of then-law professor Sunstein in both his comments on the draft of OMB Circular A-4 ${ }^{(74)}$ and in his scholarship. ${ }^{(10)} \mathrm{He}$ argues that the use of ranges is useful for informing decisions, while indicating that there is no "decisive" value for mortality risks. In related work, ${ }^{(14)}$ he has also argued for a "life-year" approach. The arguments for and against such an approach go well beyond the behavioral issues discussed here, however. ${ }^{(75,76)}$

${ }^{14}$ For example, if only U.S. studies are considered and the results are inflated to 2007 dollars, the central estimates from Mrozek and Taylor ${ }^{(78)}$ are $\$ 1.9$ million to $\$ 3.2$ million; from Viscusi and Aldy, ${ }^{(52)}$ \$6.6 million to $\$ 9.2$ million; and from Kochi, Hubbell and Kramer, ${ }^{(79)}$ \$10.7 million.
} 
risk characteristics noted earlier. As result, agencies generally adjust their estimates only for real income growth over time and for any lag (or latency) between changes in exposure and changes in incidence, discussing other differences qualitatively.

Any update to the OMB guidance should, of course, recognize the findings of more recent research. Much of this research is consistent with the standard neoclassical economic model. Ideally, the values used in benefit-cost analysis would reflect all of the attributes of the risk, including the ambiguity and fear associated specifically with that risk as described above. However, in some cases, the analyst may need to test the effects of a wide range of values either because of deficiencies in the research base or because of uncertainty regarding the applicability of the results.

Insensitivity to risk change is problematic, however. Economic theory implies that WTP should increase almost proportionately to the size of the risk change (as long as the change is small enough that income effects are negligible), which means that the VSL would be nearly constant. If WTP is not proportional to the risk change, then the corresponding VSL (equal to WTP divided by the risk change) can be very sensitive to the magnitude of the change. One possible explanation for insensitivity of WTP to risk magnitude is that individuals are indifferent between small risk changes. It appears more likely, however, that the observed insensitivity reflects misinterpretation of the probabilities, which can be reduced by using visual aids that more effectively communicate the size of the change. ${ }^{(7380)}$ While many studies that use these aids find more sensitivity to risk magnitude, others continue to find that WTP is less sensitive to risk reduction than theory implies. ${ }^{(81,82)}$ Some work ${ }^{(83,84)}$ suggests that expressing risk reductions as changes in life expectancy may lead to better comprehension of the effects of the small probabilities involved, although careful presentation is needed to ensure that the change in life expectancy is not misinterpreted as adding longevity only at the end of one's life span. We suggest using the degree of sensitivity as a criterion for evaluating the quality of studies when developing estimates for regulatory analysis, rather than assuming that it reflects indifference between risk changes of these magnitudes. ${ }^{(85,86)}$

Addressing these issues requires ensuring that valuation studies are well-designed, to help separate values that reflect misinformation or misunderstanding from values that reflect more stable and carefully-considered preferences. The current OMB guidance lists several factors that should be considered in evaluating both stated- and revealed-preference studies, which could be expanded to reflect the findings of recent behavioral research. Stability of the resulting values (across studies or over time for the same individuals) can be used as an indicator of whether the effects of behavioral factors are robust.

Stated-preference researchers have a long history of considering behavioral factors ${ }^{(87,88 \text {, }}$ ${ }^{89,5)}$ and these concerns continue to be an active area of research. For example, Hanley and Shogren ${ }^{(90)}$ describe how practices are evolving to address some of the problems raised by behavioral research, such as using workshops to better inform respondents and allowing "maybe" responses to recognize that individuals may know their preferences over only a limited range. Carlsson ${ }^{(91)}$ emphasizes the importance of providing opportunities for learning, including practice and repetition. In addition, researchers are increasingly using choice experiments that ask respondents to value varying combinations of attributes rather than a single outcome, to mimic market choices and avoid overly narrow framing of decisions.

Less attention has been paid to the implications of behavioral research for revealedpreference studies. Recent research provides insights into the extent to which such studies are likely to reflect carefully-considered preferences. In particular, Beshears et al. ${ }^{(92)}$ distinguish 
between revealed (or positive) preferences (the choices people actually make) and normative preferences (the choices people think they should make). They note that actual choices result from combining normative preferences with the sorts of decisionmaking biases and anomalies found in behavioral research. While they focus largely on savings and investment decisions, they identify a number of factors that help distinguish revealed from normative preferences, which could be useful in determining how to design revealed-preference studies for valuing nonmarket outcomes as well as in evaluating the quality of available research.

\subsection{TIME PREFERENCES}

Evaluating regulatory benefits and costs often involves comparing outcomes that occur in different time periods, using discounting to reflect time preferences. The main distinction between the traditional approach and the results of behavioral research is whether outcomes are discounted at a constant exponential rate or hyperbolically with rates that decrease over time. As discussed in Frederick et al., ${ }^{(93)}$ this distinction may reflect simplifying assumptions more than theoretical differences between the neoclassical model and behavioral research. ${ }^{15}$

One problem that arises in examining this possible divergence is the difficulty of disentangling the effect of timing from the effects of other characteristics of an outcome, such as reference dependence and loss aversion as well as aversion to risk, uncertainty, and ambiguity (which apply because the future is always uncertain). To avoid redundancy, we focus here on the effects of timing alone, while recognizing that the dividing line between pure time preferences and other types of preferences is somewhat murky. In this discussion, we address discounting the monetary value of costs and benefits, not the underlying physical impacts. When the relative values of physical outcomes depend on when they occur, it is simplest to capture this effect using time-specific monetary values rather than by using different discount rates for different outcomes.

The time period over which an analysis is conducted has important implications for discounting. We concentrate on discounting annual quantities over an intra-generational time period. We do not discuss the additional complications that arise when assessing programs (such as climate-change mitigation or radioactive-waste storage) where inter-generational impacts are of major importance. Longer-term discounting raises important concerns that go well beyond the behavioral issues discussed here, given the challenges inherent in predicting the preferences of future generations as well as questions of inter-generational equity.

\subsection{Description of the Issue}

In regulatory analysis, intra-generational benefits and costs are generally discounted using a constant (exponential) rate, selected to reflect the opportunity costs of the intervention. Regulation primarily affects private rather than government expenditures, displacing some mix of current consumption and investment. In theory, investment- and consumption-based discount rates would not diverge in perfectly competitive markets, but in actuality distortions such as taxes lead to differences. In addition, the extent to which a particular regulation displaces

\footnotetext{
${ }^{15}$ Exponential discounting can be traced to Samuelson's work on discounted utility, ${ }^{(94)}$ which was intended to

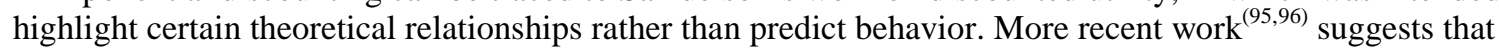
hyperbolic discounting may be consistent with the standard economic model.
} 
investments versus consumption is often unclear. Thus analysts typically test the effects of different discount rates on their results.

Time preferences have been one of the most active and well-developed components of behavioral economics research. As summarized in Chabris et al., ${ }^{(97)}$ numerous studies conducted over many years have found higher discount rates in the near term than over the longer term. As a result, behavioral economists have explored hyperbolic functions with discounted values that drop steeply in the immediate future and more gently over the longer run. ${ }^{16}$ These functions are often described as "present-biased.” In contrast, benefit-cost analysis is typically conducted with constant discount rates for intra-generational impacts; such exponential discounting assumes that time preferences are constant over different periods. ${ }^{17}$

The exponential function is the only discounting approach that yields dynamically consistent decisions when preferences are stable. ${ }^{18}$ Under hyperbolic and other functions, the preferred choice can change solely because time passes. In other words, a project that appears desirable (i.e., the present value of its net benefits is positive) in time period 1 may appear undesirable (i.e., have a negative net present value) in time period 2. ${ }^{(101)}$ This inconsistency is often referred to as a "preference reversal" although it can perhaps be better characterized as a sort of tug-of-war between the two time perspectives or "as a game between a sequence of shortrun impulsive selves and a long-run patient self” (Fudenberg and Levine, ${ }^{(102)}$ p. 1449).

Many of the studies that find declining rates were conducted in laboratory settings; declining rates have also been found in some field studies that address real-world behavior. While these studies often demonstrate hyperbolic discounting, this pattern appears to apply primarily to relatively short near-term periods. Frederick et al. ${ }^{(93)}$ review recent studies, finding that if they exclude studies with time horizons less than one year, discount rates no longer decline over time, clustering around an average annual discount factor of 0.8 . This factor implies an annual discount rate of 25 percent, however, well above market rates. Frederick et al. note that the high rates may be due to the effects of several confounding factors that tend to bias upward the discount rates estimated in these studies.

Laibson et al. ${ }^{(103)}$ explore time preferences over the life-cycle more systematically, using a structural model with data on age-specific income, credit-card borrowing, marginal propensity to consume, retirement-wealth accumulations, household characteristics, mortality rates, and other factors. If they restrict their model to a single (exponential) function, they find an annual discount rate of about 16.7 percent. However, their modeling rejects this single rate hypothesis. Allowing a quasi-hyperbolic function, they find a short-term annualized discount rate of 40 percent and a long-term annualized rate of 4.3 percent.

Behavioral economists have explored a number of motivations behind these patterns. The high near-term rates are often described as resulting from imperfect self-control, which leads individuals to seek immediate gratification even if it diverges from their own longer-term

\footnotetext{
${ }^{16}$ Alternatives to the hyperbolic discounting model have been proposed by some to explain these research results, including subadditive discounting ${ }^{(98)}$ and similarity relations. ${ }^{(99)}$

${ }^{17}$ With exponential discounting the present value (PV) of a benefit or cost $(\mathrm{S})$ at time (t) using a discount rate (r) is calculated as $\mathrm{PV}=\mathrm{S} /(1+\mathrm{r})^{\mathrm{t}}$.

${ }^{18}$ Harvey $^{(100)}$ describes how decisions can remain dynamically consistent with hyperbolic discounting, e.g., when individuals systematically decrease their discount rates as time passes.
} 
preferences. ${ }^{19}$ Examples of this behavior, such as eating dessert despite wanting to lose weight, are abundant.

\subsection{Implications for Regulatory Analysis}

OMB Circular A-4 ${ }^{(5)}$ recommends exponential discounting using two real annual rates: 7 percent to approximate the average marginal pretax rate of return on private investments and 3 percent to reflect consumption time preferences (the "social rate of time preference"). OMB derives the 3 percent rate from the pretax rate of return on long-term government debt to approximate the interest paid on savings, assuming that the savings rate represents the average by which consumers discount future consumption. (As noted earlier, the use of alternative rates reflects uncertainty about whether these programs primarily affect investment or consumption.) OMB also requires that agencies provide a schedule that shows how the undiscounted costs and benefits will be distributed over time and discusses the use of alternative rates in sensitivity analysis.

The results of behavioral research pose two challenges to this guidance: (1) they suggest significant differences between short- and long-term discount rates, leading to hyperbolic rather than exponential functions; and (2) they suggest that individual behavior reveals time preferences that differ from market rates. Determining the implications of these findings for regulatory benefit-cost analysis requires clearly defining what it is that we are trying to measure.

For regulatory analysis, rates reflecting a longer-term view (e.g., greater than one year) appear more appropriate than the high near-term rates found in behavioral research (regardless of whether they are exponential or hyperbolic) for two reasons. First, these regulations are generally expected to remain in place over a several years, which implies that the planning horizon is consistent with longer-term rates. Second, these regulations are focused on providing lasting (rather than temporary) improvements in welfare. ${ }^{20}$ To the extent that short-term rates reflect impulsive behavior and self-control problems (rather than more thoughtful consideration), they are inconsistent with this goal. To reflect improvements in social welfare, it appears desirable to focus on the time preferences that result from more careful assessment of long-range wellbeing. $^{21}$

Market rates appear more appropriate than individual rates in this context. Benefit-cost analysis is designed to provide information on the trade-offs inherent in spending on particular regulatory goals rather than on other goods and services; i.e., the opportunity costs of diverting resources from other types of investment or consumption. ${ }^{22}$ Market rates reflect forgone investment or consumption; they are prices that result from supply and demand conditions that

\footnotetext{
${ }^{19}$ Researchers are also exploring the potential neurological basis of the tendency to discount hyperbolically. ${ }^{(97,105)}$ For more general discussion of the economic implications of neuroscience research, see Loewenstein et al. ${ }^{(105)}$ and Harrison and Ross. ${ }^{(106)}$

${ }^{20}$ As discussed in OMB Circular A-4, more generally the rationale for government intervention is the existence of market failures or other social purposes (such as redistributing resources or preventing discrimination).

${ }^{21}$ This does not mean that short-term rates should be completely ignored: they may play an important role in predicting behavior. For example, individuals may exhibit hyperbolic discounting in deciding whether to purchase a more fuel efficient car or light bulb. Once the behavioral response to a regulation has been predicted, the costs and benefits associated with these responses should be discounted using the approaches considered in this section.

${ }^{22}$ As Sunstein and Rowell ${ }^{(105)}$ note "...if the interests of future generations are put to one side, and if we focus solely on risks faced by those now living, regulatory benefits should be discounted at the same rate as money, and for a simple reason: existing valuations depend on willingness to pay, and discounting those valuations is simply a matter of discounting money” (p. 173).
} 
reflect production technology and consumer preferences. Thus market rates may differ from the rates found in studies that focus solely on individual preferences, while at the same time incorporating individual preferences, including any effects of behavioral anomalies or biases.

Discounting also requires considering the conditions under which it may be desirable to substitute other information on individual preferences for market prices. For outcomes such as environmental improvements and health-risk reductions (discussed in Sections 4 and 5), we lack market prices and are dependent on other forms of research to determine monetary values. In these cases, we need to think carefully about how behavioral issues may affect the estimated values. For discounting, market prices are available, which already incorporate the effect of behavioral anomalies.

However, improved understanding of the behavioral findings would be useful, given the influence of individual preferences on market rates. While the reviews of this research (e.g., Frederick et al. ${ }^{(91)}$ ) compile the results of numerous studies, they do not evaluate these studies against criteria for quality or for applicability to regulatory policy. Systematic review is needed both to determine the extent to which discount rates might decrease over time (and whether they may be close-to-constant over the long run as suggested by Frederick et al.) and the extent to which they might differ from the 3 percent to 7 percent range now used. In the meantime, the OMB requirements seem sensible, given that they are based on market rates, include sensitivity analysis, and require presentation of the schedule of undiscounted costs and benefits for inspection by decisionmakers. Simply summarizing costs and benefits as a net present value does not provide adequate information given uncertainty about the appropriate discount rates and patterns.

\subsection{A PRAGMATIC ROLE FOR BENEFIT-COST ANALYSIS}

While benefit-cost analysis is used to inform normative judgments (what policy "ought" to be adopted), it relies on information about the behavior and preferences of those affected. Thus it contains a strong descriptive or positive element. ${ }^{23}$ Behavioral economics adds to the complexity of this task, suggesting that individuals' choices may not reflect their preferences nor necessarily coincide with their own self-defined long-term welfare. Thus behavioral economics poses a difficult challenge for analysts: should they rely unquestioningly on individual's choices as indicators of their preferences, or accept only those that appear to be rational and welfareenhancing?

It seems clear one should incorporate behavioral-economic findings into the positive model used to forecast the consequences of adopting a policy so as to make the forecast as accurately as possible. The harder question is how to evaluate the desirability of the consequences. One possible response is to substitute a paternalistic approach for the positive model, placing the analyst and/or policymaker in the position of deciding which preferences are rational and welfare-enhancing and which are not. ${ }^{24}$ An alternative is to continue to work on developing information on the preferences that emerge when individuals are well-informed and have the opportunity for reflection, recognizing that complex attributes of regulatory programs as well as the complexities of human judgment mean that our understanding of these preferences will always be somewhat imperfect.

\footnotetext{
${ }^{23}$ Whether benefit-cost analysis is primarily a normative or positive exercise is discussed in detail elsewhere. ${ }^{(108,109)}$

${ }^{24}$ One problem with this approach, as Smith ${ }^{(108)}$ notes, is that experts make mistakes too, and there is no consensus on whose expert judgment should prevail.
} 
Fortunately, the approaches currently used in benefit-cost analysis provide several practical tools for dealing with these uncertainties. These tools include quantitative sensitivity, probabilistic, and breakeven analysis, qualitative discussion of the implications of concerns that cannot be easily quantified, and explicit recognition that benefit-cost analysis should be only one of several inputs to policy decisions.

These concerns suggest a more pragmatic role for benefit-cost analysis than indicated by either the simplified version of the standard economic model or by behavioral economics. Wellconducted benefit-cost analysis provides the analyst with several advantages. It offers an established approach for identifying and assessing the physical and economic effects of different policy options that reflects the preferences of those affected to the extent possible. It is best viewed as one of many sources of information for decisionmaking rather than as providing "the" answer to a policy question.

This pragmatic role is reflected in Sunstein's scholarship. As he argues, benefit-cost analysis "is most plausibly justified on cognitive grounds - as a way of counteracting predictable problems in individual and social cognition" (Sunstein, ${ }^{(10)}$ p. 1059); it provides information that can be used to counterbalance potential decisionmaking errors. The use of ranges and sensitivity analysis are also consistent with his recommendations for dealing with uncertain values and with his recognition that benefit-cost analysis can be informative even if it is not decisive. These themes are echoed in Circular A-4, which emphasizes that the goal of regulatory analysis is to provide information and requires assessment of uncertainty. Behavioral economics can be viewed as adding dimensions for consideration. ${ }^{25}$

The core issue raised by behavioral economics for benefit-cost analysis is whether choices in fact reflect welfare-enhancing preferences. The answer to this question appears to be "it depends." In some cases, behavioral research has identified attributes that individuals may truly value that are not explicitly incorporated into the standard economic model. In other cases, decisions may reflect simplifying heuristics or emotional responses that drive a wedge between choices and normative preferences. We are far from fully understanding these distinctions, but the questions raised by behavioral economics provide useful insights for how we might further explore these issues. While benefit-cost analysis is useful for many reasons, it will inevitably have limitations. Clear discussion of its implications and uncertainties will always be required.

\section{ACKNOWLEDGEMENTS}

This article builds on a paper we drafted to support Toward Principles and Standards in the Use of Benefit-Cost Analysis (2010), by Richard O. Zerbe, Jr., Tyler Blake Davis, Nancy Garland, and Tyler Scott, with funding from the John D. and Catherine T. MacArthur Foundation. Dr. Hammitt received additional support from INRA and the European Research Council under the European Community’s Seventh Framework Programme (FP7/2007-2013) Grant Agreement no. 230589.

\footnotetext{
${ }^{25}$ The OMB Circular was developed under the leadership of then-Office of Information and Regulatory Affairs Administrator John Graham; Sunstein was one of the peer reviewers of the draft. ${ }^{(74)}$ Although Graham has voiced disagreement with some of Sunstein's scholarship, he emphasizes similar themes such as the value of benefit-cost analysis as a comprehensive framework for evaluating policy, the need to characterize uncertainty about effects and values, the importance of considering nonquantified effects, and equity. ${ }^{(7)}$
} 


\section{REFERENCES}

1. U.S. Office of Management and Budget. 2010 Report to Congress on the Benefits and Costs of Federal Regulations and Unfunded Mandates on State, Local, and Tribal Entities. U.S. Office of Management and Budget: Washington, DC, 2010.

2. Clinton WJ. Executive Order 12866: Regulatory planning and review. Federal Register, 1993; 58(190):51735-51744.

3. Reagan R. Executive Order 12291: Federal regulation. Federal Register, 1981; 46(190):1319313198.

4. Obama B. Executive Order 13563: Improving regulation and regulatory review. Federal Register, 2011;76(14):3821-3823.

5. U.S. Office of Management and Budget. Circular A-4: Regulatory Analysis. U.S. Office of Management and Budget: Washington, DC, 2003.

6. U.S. Office of Management and Budget. Agency Checklist: Regulatory Impact Analysis. U.S. Office of Management and Budget: Washington, DC, 2010.

7. Graham JD. Saving lives through administrative law and economics. University of Pennsylvania Law Review, 2008; 157:395-540.

8. Kahneman D, Knetsch JL, Thaler RH. Anomalies: The endowment effect, loss aversion, and status quo bias. Journal of Economic Perspectives, 1991; 5(1):192-206.

9. Thaler RH, Sunstein CR. Nudge: Improving Decisions about Health, Wealth, and Happiness. New Haven: Yale University Press, 2008.

10. Sunstein CR. Cognition and benefit-cost analysis. Journal of Legal Studies, 2000; 29:10591103.

11. Hahn R, Sunstein CR. A new executive order for improving federal regulation. University of Pennsylvania Law Review, 2002; 150:1489-1552.

12. Sunstein CR. The arithmetic of arsenic. Georgetown Law Journal, 2002; 90(7):2255-2309.

13. Sunstein CR. Risk and Reason. Cambridge and New York: Cambridge University Press, 2002.

14. Sunstein CR. Lives, life-years and willingness to pay. Columbia Law Review, 2004; 104 : 205-252.

15. Sunstein CR. Willingness to pay vs. welfare. Harvard Law and Policy Review, 2007; 1:303330. 
16. U.S. Office of Management and Budget. Disclosure and Simplification as Regulatory Tools. Memorandum for the Heads of Executive Departments and Agencies, from Cass R. Sunstein, Administrator, Office of Information and Regulatory Affairs. 2010.

17. Sunstein CR. Executive Order 13563, "Improving regulation and regulatory review” Memorandum for the Heads of Executive Departments and Agencies, and of Independent Regulatory Agencies, from the Administrator, Office of Information and Regulatory Affairs. M11-10, 2011.

18. Thaler RH, Mullainathan S. How behavioral economics differs from traditional economics. The Concise Encyclopedia of Economics, 2008.

19. Jones-Lee MW. Altruism and the value of other people's safety. Journal of Risk and Uncertainty, 1991; 4(2):213-219.

20. Bergstrom TC. Benefit-cost in a benevolent society. American Economic Review, 2006; 96(1):339-351.

21. Krutilla J. Conservation reconsidered. American Economic Review, 1967; 57(4):777-786.

22. Machina MJ. "Expected utility” analysis without the independence axiom. Econometrica, 1982; 50:277-323.

23. Machina MJ. Dynamic Consistency and non-expected utility models of choice under uncertainty. Journal of Economic Literature, 1989; 27:1622-1668.

24. Kahneman D, Tversky A. Prospect theory: An analysis of decision under risk. Econometrica, 1979; 47(2):263-91.

25. Kahneman D, Tversky A, Slovic P, editors. Judgment under Uncertainty: Heuristics and Biases. Cambridge: Cambridge University Press, 1982.

26. Thaler RH. The Winner’s Curse. Princeton: Princeton University Press, 1992.

27. Kahneman D, Tversky A, editors. Choices, Values, and Frames. Cambridge: Cambridge University Press, 2000.

28. Camerer CF, Loewenstein G, Rabin M, editors. Advances in Behavioral Economics. Princeton: Princeton University Press, 2004.

29. Rabin M. Psychology and economics. Journal of Economic Literature, 1998; 36:11-46.

30. Fudenberg D. Advancing beyond “Advances in Behavioral Economics.” Journal of Economic Literature, 2006; 44:694-711. 
31. DellaVigna S. Psychology and economics: Evidence from the field. Journal of Economic Literature, 2009; 47(2):315-372.

32. Ariely D. Predictably Irrational. New York: Harper Collins, 2008.

33. Bernheim BD, Rangel A. Behavioral public economics: Welfare and policy analysis with non-standard decision-makers. In: Diamond $\mathrm{P}$ and Vartiainen $\mathrm{H}$, editors. Economic Institutions and Behavioral Economics. Princeton: Princeton University Press, 2007.

34. Bernheim, BD, Rangel A. Beyond revealed preference: Choice-theoretic foundations for behavioral welfare economics. Quarterly Journal of Economics, 2009; 124(1):51-104.

35. Sugden R. The opportunity criterion: Consumer sovereignty without the assumption of coherent preferences. American Economic Review, 2004; 94(4):1014-1033.

36. Sugden R. Coping with preference anomalies in benefit-cost analysis: A market simulation approach. Environmental and Resource Economics, 2005; 32(1):129-160.

37. Sugden R. Market simulation and the provision of public goods: A non-paternalistic response to anomalies in environmental evaluation. Journal of Environmental Economics and Management, 2009; 57(1):87-103.

38. Smith VK, Moore EM. Behavioral economics and benefit cost analysis. Environment and Resource Economics, 2010; 46(2):217-234.

39. Charness G, Rabin M. Understanding preferences with simple tests. Quarterly Journal of Economics, 2002; 117(3):817-869.

40. Subramanian U, Cropper M.. Public choices between life saving programs: The tradeoff between qualitative factors and lives saved. Journal of Risk and Uncertainty, 2000; 21(1):117149.

41. Bosworth, R, Cameron TA, DeShazo JR. Demand for environmental policies to improve health: Evaluating community-level policy scenarios. Journal of Environmental Economics and Management, 2009; 57(3):293-308.

42. Bosworth R, Cameron TA, DeShazo JR. Is an ounce of prevention worth a pound of cure? Comparing demand for public prevention and treatment policies. Medical Decision Making, 2010; 30(4):E40-E56.

43. Willig RD. Consumer's surplus without apology. The American Economic Review, 1976; 66(4):589-597.

44. Hanemann WM. Willingness to pay and willingness to accept: How much can they differ? American Economic Review, 1991; 81:635-647. 
45. Horowitz JK, McConnell KE. A review of WTA/WTP studies. Journal of Environmental Economics and Management, 2002; 44(3):426-447.

46. Knetsch JL. Gains, losses, and the US-EPA economic analysis guidelines: A hazardous product? Environmental and Resource Economics, 2005; 32(1):91-112.

47. Knetsch JL. Values of gains and losses: Reference states and choices of measure.

Environment and Resource Economics, 2010; 46(2):179-188.

48. Freeman AM III. The Measurement of Environmental and Resource Values: Theory and Methods (Second Edition). Washington D.C.: Resources for the Future, 2003.

49. Samuelson W, Zeckhauser RJ. Status quo bias in decision making. Journal of Risk and Uncertainty, 1988; 1:57-159.

50. Pratt JW, Zeckhauser RJ. Willingness to pay and the distribution of risk and wealth. Journal of Political Economy, 1996; 104:747-763.

51. Hammitt JK, Treich N. Statistical vs. identified lives in benefit-cost analysis. Journal of Risk and Uncertainty, 2007; 35(1):45-66.

52. Viscusi WK, Aldy JE. The value of a statistical life: A critical review of market estimates throughout the world. Journal of Risk and Uncertainty, 2003; 27(1):5-76.

53. Lindhjem H, Navrud S, Braathen NA. Valuing Lives Saved from Environmental, Transport, and Health Policies: A Meta-Analysis of Stated Preference Studies. Paris: Organization for Economic Co-operation and Development, ENV/EPOC/WPNEP(2008)10/FINAL, 2010.

54. U.S. Environmental Protection Agency. The Benefits and Costs of the Clean Air Act: 1990 to 2020. Washington, DC: U.S. Environmental Protection Agency, 2011.

55. U.S. Department of Transportation, National Highway Traffic Safety Administration. Final Regulatory Impact Analysis, FMVSS No. 126: Electronic Stability Control Systems, 2007.

56. U.S. Food and Drug Administration. Food labeling; trans fatty acids in nutrition labeling; Consumer research to consider nutrient content and health claims and possible footnote or disclosure statements; Final rule and proposed rule. Federal Register, 2003; 68(133):4143441506.

57. Hammitt JK. Valuing mortality risk: Theory and practice. Environmental Science and Technology, 2000; 34:1396-1400.

58. U.S. Environmental Protection Agency. Valuing Mortality Risk Reductions for Environmental Policy: A White Paper (Review Draft). Prepared by the National Center for Environmental Economics for consultation with the Science Advisory Board-Environmental Economics Advisory Committee, 2010. 
59. Shepard DS, Zeckhauser RJ. Survival versus consumption. Management Science, 1984 ; 30:423-439.

60. Rosen S. The value of changes in life expectancy. Journal of Risk and Uncertainty,1988; $1: 285-304$.

61. Hammitt JK. Valuing changes in mortality risk: Lives saved versus life years saved. Review of Environmental Economics and Policy, 2007; 1(2):228-240.

62. Hammitt JK, Robinson LA. The income elasticity of the value per statistical life: Transferring estimates between high and low income populations. Journal of Benefit-Cost Analysis, 2011; 2(1):Art. 1.

63. Robinson LA, Hammitt JK, Aldy JE, Krupnick A, Baxter J. Valuing the risk of death from terrorist attacks. Journal of Homeland Security and Emergency Management, 2010; 7(1):Art. 14.

64. Sunstein CR. Bad deaths. Journal of Risk and Uncertainty, 1997; 14:259-282.

65. Sunstein CR. Terrorism and probability neglect. Journal of Risk and Uncertainty, 2003; 26(2/3):121-136.

66. Adler MA. Fear assessment: Cost-benefit analysis and the pricing of fear and anxiety. Chicago Kent Law Review, 2004; 79(3):977-1053.

67. Ellsberg D. Risk, ambiguity, and the Savage axioms. The Quarterly Journal of Economics, 1961; 75(4):643-669.

68. Viscusi WK, Magat WA, Huber J. Communication of ambiguous risk information. Theory and Decision, 1991; 31:159-173.

69. Shogren JF. Economics of diet and health: Research challenges. Acta Agriculturae Scand Section C, 2005; 2:117-127.

70. Riddel M, Shaw WD. A theoretically-consistent empirical model of non-expected utility: An application to nuclear-waste transport. Journal of Risk and Uncertainty, 2006; 32:131-150.

71. Johansson-Stenman O. Mad cows, terrorism and junk food: Should public policy reflect perceived or objective risks? Journal of Health Economics, 2008; 27(2):234-248.

72. Hammitt JK, Graham JD. Willingness to pay for health protection: inadequate sensitivity to probability? Journal of Risk and Uncertainty, 1999; 18(1):33-62.

73. Corso PS, Hammitt JK, Graham JD. Valuing mortality-risk reduction: Using visual aids to improve the validity of contingent valuation. Journal of Risk and Uncertainty, 2001; 23(2):165184. 
74. Sunstein CR. Draft guidelines. Memorandum to the Office of Information and Regulatory Affairs, 2003.

75. Cropper M, et al. SAB advisory on EPA's issues in valuing mortality risk reduction. Memorandum from the Chair, Science Advisory Board, and the Chair, Environmental Economics Advisory Committee, to EPA Administrator Stephen L. Johnson. Washington, DC: U.S. Environmental Protection Agency, EPA-SAB-08-001, 2007.

76. National Academy of Sciences. Estimating mortality risk reduction and economic benefits from controlling ozone air pollution. Committee on Estimating Mortality Risk Reduction Benefits from Decreasing Tropospheric Ozone Exposure. Washington D.C.: National Academies Press, 2008.

77. Robinson LA, Hammitt JK. Valuing health and longevity in regulatory analysis: Current issues and challenges. In: Levi-Faur, editor. Handbook on the Politics of Regulation. Cheltenham, UK and Northampton, MA: Edward Elgar, 2011.

78. Mrozek JR, Taylor LO. What determines the value of life? A meta-analysis. Journal of Policy Analysis and Management, 2002; 21(2):253-270.

79. Kochi I, Hubbell B, Kramer R. An empirical Bayes approach to combining and comparing estimates of the value of a statistical life for environmental policy analysis. Environmental and Resource Economics, 2006; 34:385-406.

80. Hammitt JK, Haninger K, Valuing fatal risks to children and adults: Effects of disease, latency, and risk aversion. Journal of Risk and Uncertainty, 2010; 40(1):57-83.

81. Alberini A, Cropper M, Krupnick A, Simon N. Does the value of a statistical life vary with age and health status? Evidence from the U.S. and Canada. Journal of Environmental Economics and Management, 2004; 48(1):769-792.

82. Hammitt JK, Haninger K, Willingness to pay for food safety: Sensitivity to duration and severity of illness. American Journal of Agricultural Economics, 2007; 89(5):1170-1175.

83. Morris J, Hammitt JK. Using life expectancy to communicate benefits of health care programs in contingent valuation studies. Medical Decision Making, 2001; 21:468-478.

84. Desaigues B, Rabl A, Ami D, Kene BM, Masson S, Salomon M-A, Santoni L. Monetary value of a life expectancy gain due to reduced air pollution: Lessons from a contingent valuation. Revue d'Economie Politique, 2007; 117 (5):675-698.

85. Hammitt JK. Evaluating contingent valuation of environmental health risks: The proportionality test. Association of Environmental and Resource Economists Newsletter, 2000: 20(1):14-19. Reprinted in Stated Preference: What Do We Know? Where Do We Go? 
(Proceedings), U.S. Environmental Protection Agency: Washington, DC, Report number EE0436, October 2000.

86. Cropper M, Hammitt JK, Robinson LA. Valuing “statistical” lives: Progress and challenges. In Rausser, G. editor. Annual Review of Resource Economics, 2011.

87. Mitchell RC, Carson RT. Using Surveys to Value Public Goods: The Contingent Valuation Method. Washington, DC: Resources for the Future, 1989.

88. National Oceanic and Atmospheric Administration. Natural resource damage assessments under the Oil Pollution Act of 1990. Federal Register, 1993; 58(10):4601-4614.

89. U.S. Environmental Protection Agency. Guidelines for Preparing Economic Analysis. Washington, DC: U.S. Environmental Protection Agency, EPA 240-R-10-001, 2010.

90. Hanley N, Shogren JF. Is benefit-cost analysis anomaly-proof? Environmental and Resource Economics, 2005; 32(1):13-34.

91. Carlsson F. Design of stated preference surveys: Is there more to learn from behavioral economics? Environment and Resource Economics, 2010; 46(2):167-177.

92. Beshears J, Choi, JJ, Laibson D, Madrian BC. How are preferences revealed? Journal of Public Economics, 2008; 92:1787-1794.

93. Frederick S, Loewenstein G, O’Donoghue T. Time discounting and time preference: A critical review. Journal of Economic Literature, 2002; 40:351-401.

94. Samuelson PA. A Note on the measurement of utility. Review of Economic Studies, 1937; 4(2):155-161.

95. Weitzman ML. Gamma discounting. The American Economic Review, 2001; 91(1):260-271.

96. Gollier C, Zeckhauser R. Aggregation of heterogeneous time preferences. Journal of Political Economy, 2005; 113(4):878-896.

97. Chabris CF, Laibson DI, Schuldt JP. Intertemporal Choice. In: Durlauf SN, Blume LE, editors. The New Palgrave Dictionary of Economics (Second Edition). New York: Palgrave Macmillan, 2008.

98. Read D. Is time-discounting hyperbolic or subadditive? Journal of Risk and Uncertainty, 2001; 23(1):5-32.

99. Rubinstein A. "Economics and psychology”? The case of hyperbolic discounting. International Economic Review, 2003; 44(4):1027-1216. 
100. Harvey CM. The reasonableness of non-constant discounting, Journal of Public Economics, 1994; 53:31-51.

101. Laibson DI. Golden eggs and hyperbolic discounting. Quarterly Journal of Economics, 1997;1 12(2):443-478.

102. Fudenberg D, Levine DK. A dual-self model of impulse control. American Economic Review, 2006; 96(5):1449-1476.

103. Laibson DI, Repetto A, Tobacman J. Estimating discount functions with consumption choices over the lifecycle. Unpublished manuscript, 2007.

104. Berns, GS, Laibson D, Loewenstein G. Intertemporal choice - Toward an integrative framework. Trends in Cognitive Sciences, 2007; 11(11):482-488.

105. Loewenstein G, Rick S, Cohen JD. Neuroeconomics. Annual Review of Psychology, 2008; 59:647-672.

106. Harrison G, Ross D. The methodologies of neuroeconomics. Journal of Economic Methodology, 2010; 17(2):185-196.

107. Sunstein CR, Rowell A. On discounting regulatory benefits: Risk, money, and intergenerational equity. University of Chicago Law Review, 2007; 74:171-208.

108. Adler MA, Posner EA. New Foundations for Benefit-Cost Analysis. Cambridge: Harvard University Press, 2006.

109. Hammitt JK. Response: Saving lives: Benefit-cost analysis and distribution. University of Pennsylvania Law Review PENNumbra, 2009; 157:189-199.

110. Smith VK. Reflections on the literature. Review of Environmental Economics and Policy, 2007; 1(1):152-165. 